\title{
IS IS
}

Extended Abstract

\section{On the GeoGebra supported collaborative learning}

\author{
Đurđica Takači $^{1}{ }^{*}$ Gordana Stankov $^{2} *$ Miroslav Marić $^{3, *}$ \\ ${ }^{1}$ Faculty of Natural Sciences, University of Novi Sad, / Trg Dositeja Obradovića 4, Novi Sad, Serbia \\ ${ }^{2}$ Subotica Tech - College of Applied Sciences, Subotica, / Marka Oreškovića 16, Subotica, Serbia \\ ${ }^{3}$ Faculty of Mathematics, University of Belgrade, / Studentski trg 15, Belgrade, Serbia
}

E-Mails: djtak@dmi.uns.ac.rs

* Tel.: +381-21-485-2857; Fax: +381-21-450-485

Accepted:

\section{Introduction}

In our research the collaborative learning with and without the use of the computer is analyzed. The process of collaborative learning is applied to the first year calculus students at the University of Novi Sad, Serbia, for examining functions and drawing their graphs. The collaborative learning process was analyzed, compared and described, for experimental and control group regarding their way of learning. First part of research was conducted in 2011 and 2012, were both experimental and control group were divided to small four member groups by using Kagan's (1994) principles. In 2013 the new experimental group was formed by using mathematical model for the group making.

The students in both experimental groups learned with the help of GeoGebra, and the students in the control group learned without using GeoGebra.

After the collaborative learning, the students were tested with a test and post test, and the results of the experimental groups were significantly better than the results of students in the control group.

The results are of the first part of research is published in the paper Takači et al (2015). 


\section{Methods}

The research had started in 2011 year with the control group with 180 students, and continued in 2012 with the experimental group. In 2012 we had 210 students, but 180 students were chosen for experimental group having a corresponding student from 2011, same major, according to the pre-test results.

Both the experimental and the control group were structured according to Kagan's, instructions:

- The results of the pre-tests considering their pre-calculus knowledge were used to form a list order of all the students (ranging from the worst to the best one).

- Each student had to make two lists of persons whom he likes or dislikes, particularizing up to three names.

The research was continued in 2013 when the second experimental group is formed analogously as in 2012, but the small four members groups are formed by using variable neighborhood search algorithm, (metaheuristic for solving the mathematical optimization problems) based on Kagan's (1994) principles. The students also worked with the help of Geogebra.

The task for all students was to examine twenty 20 appropriate functions and draw their graphs. The calculations for chosen functions could be done easily even without computer. The control group finished their task in two weeks ( 2 times 5 classes a week), but both experimental groups finished the whole task in 5 hours. The students worked on the task at the university, with the help of the authors. All the members in the group were given 5 points (of 100) for the successfully finished task, both in experimental and control group.

After collaborative learning the students got test (colloquium) and post test (exam) to be done without the computer.

\section{Results and Discussion}

The analysis of the students work (examining 20 functions) had confirmed that learning calculus with the use of GeoGebra is more "constructivist" than without computer. Students used the opportunities to consider together algebraic and graphic view in order to examine, analyze and test the adequacy of their knowledge of the properties of functions. The students used the characteristics of the package GeoGebra to analyze both the formula and its graph at the same time in different ways. Both experimental groups finished all 20 tasks with the precision of $18.02 \%$ (2012), 18.25\%, (2013), but the control group finished all 19.64 tasks with the precision of $12.84 \%$.

The statistical analysis (t-test, effect size) proves that the students' learning achievement in examining functions and drawing their graphs is better when they use GeoGebra.

The difference between the results of the test and post tests was statistically significant at the level of significance of 0.05 and 0.01 , regarding control and both experimental groups. 


\section{Conclusions}

Taking into account the results of the students' achievement both at the test and the post-test, the results of the interviews, and the average number of solved tasks (of 20) per one group, we can say that the learning of examining functions and drawing their graphs by GeoGebra in CSCL groups is more efficient than the learning without it in collaborative groups.

Since the difference between the tested experimental groups, of pre test, and post test was not statistically significant at the level of significance of 0.0505 and 0.01 , it can be concluded that the application of variable neighborhood search algorithm is very useful for team building procedure when we have lot of students to work with.

\section{References and Notes}

1. Kagan, S. (1994). Cooperative Learning. San Clemente, CA: Resources for Teachers,Inc.

2. O'Malley, C. (ed.) (1995). Computer-supported cooperative learning. Berlin: Springer- Verlag.

3. Tall, D. (2011). A Sensible approach to the Calculus. Handbook Calculus and its teaching. Ed. F. Pluminage and A. Cuevas.

4. Takači, Dj., Stankov, G., Milanovic, I., (2015) Efficiency of learning environment using GeoGebra when calculus contents are learned in collaborative groups, Computers \& Education 82: 421-431

(C) 2015 by the authors; licensee MDPI and ISIS. This abstract is distributed under the terms and conditions of the Creative Commons Attribution license. 